\title{
VARIANT FORMATION AND DISTRIBUTION OF MEDIAN NERVE
}

\section{Deepa Devadas *, Jessie James, Ganesh Nathuramji Trivedi.}

Andaman and Nicobar Islands Institute of Medical Sciences, Atlanta Point, Port Blair, Andaman \& Nicobar Islands - 744104, India.

\section{ABSTRACT}

During routine cadaveric dissection while teaching undergraduate medical students, the median nerve on the left upper limb of a 60 year old female cadaver showed presence of an accessory lateral root arising from lateral cord of brachial plexus.It also pierced brachialis muscle in the arm before reaching cubital fossa. Knowledge of these variations is helpful in evaluating nerve injury and preventing complications during anaesthetic and surgical procedures in the axilla.

KEY WORDS: Median nerve, variant, accessory root, Brachialis.

Address for Correspondence: Dr. Deepa Devadas, Andaman and Nicobar Islands Institute of Medical Sciences, Atlanta Point, Port Blair, Andaman \& Nicobar Islands - 744104, India.

E-Mail: deepadevadas108@gmail.com

Access this Article online

Quick Response code

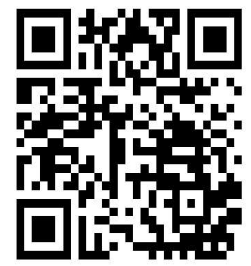

DOI: $10.16965 /$ ijar.2018.280

\begin{tabular}{|c|c|c|}
\hline \multicolumn{3}{|c|}{ Journal Information } \\
\hline \begin{tabular}{|c} 
International Journ \\
$\begin{array}{c}\text { ICV for } 2016 \\
90.30\end{array}$ \\
ISSN (E) 2321- \\
https://w
\end{tabular} & $\begin{array}{l}\text { Anatomy and Res } \\
\text { ISSN (P) 2321-8967 } \\
\text { hr.org/ijar.htm }\end{array}$ & ch \\
\hline \multicolumn{3}{|c|}{ Article Information } \\
\hline $\begin{array}{l}\text { Received: } 08 \text { Jun } 2018 \\
\text { Peer Review: } 08 \text { Jun } 2018 \\
\text { Revised: None }\end{array}$ & $\begin{array}{l}\text { Accepted: } 17 \text { Jul } 2 \\
\text { Published (O): } 10 \\
\text { Published (P): } 10\end{array}$ & 2018 \\
\hline
\end{tabular}

\section{INTRODUCTION}

Median nerve, an important branch of brachial plexus, is one of the main nerves supplying the upper limb. The median nerve has two roots from the lateral $(C 5,6,7)$ and medial $(C 8, T 1)$ cords, which embrace the third part of the axillary artery, and unite anterior or lateral to it. The median nerve enters the arm and crosses the brachial artery from lateral to medial side near the insertion of coracobrachialis. It then descends into the cubital fossa where it lies posterior to the bicipital aponeurosis and anterior to brachialis, separated by the latter from the elbow joint.It gives off vascular branches to the brachial artery and usually a branch to pronator teres, a variable distance proximal to the elbow joint [1]. The median nerve does not give any other branches in the arm. Here the authors report a case of numerical variation in the origin of median nerve where it was formed by the union of one medial and two lateral roots. The variant median nerve was also found to supply the brachialis muscle in the arm. A clear understanding of the median nerve anatomy with its possible variations will prove helpful to the judicious clinician in evaluating nerve injury as well as preventing iatrogenic nerve damage and subsequent complications.

\section{CASE REPORT}

During routine dissection for teaching undergraduate medical students, a unilateral variation was observed in the formation of the median nerve in the left upper limb of a 60 year old female cadaver. It was observed that the left median nerve was formed by the union of two lateral roots arising from lateral cord and a single medial root arising from medial cord of brachial plexus respectively. The lateral root (R2),after arising from the lateral cord of brachial plexus 
Fig. 1: Showing median nerve with accessory root and supplying brachialis muscle.

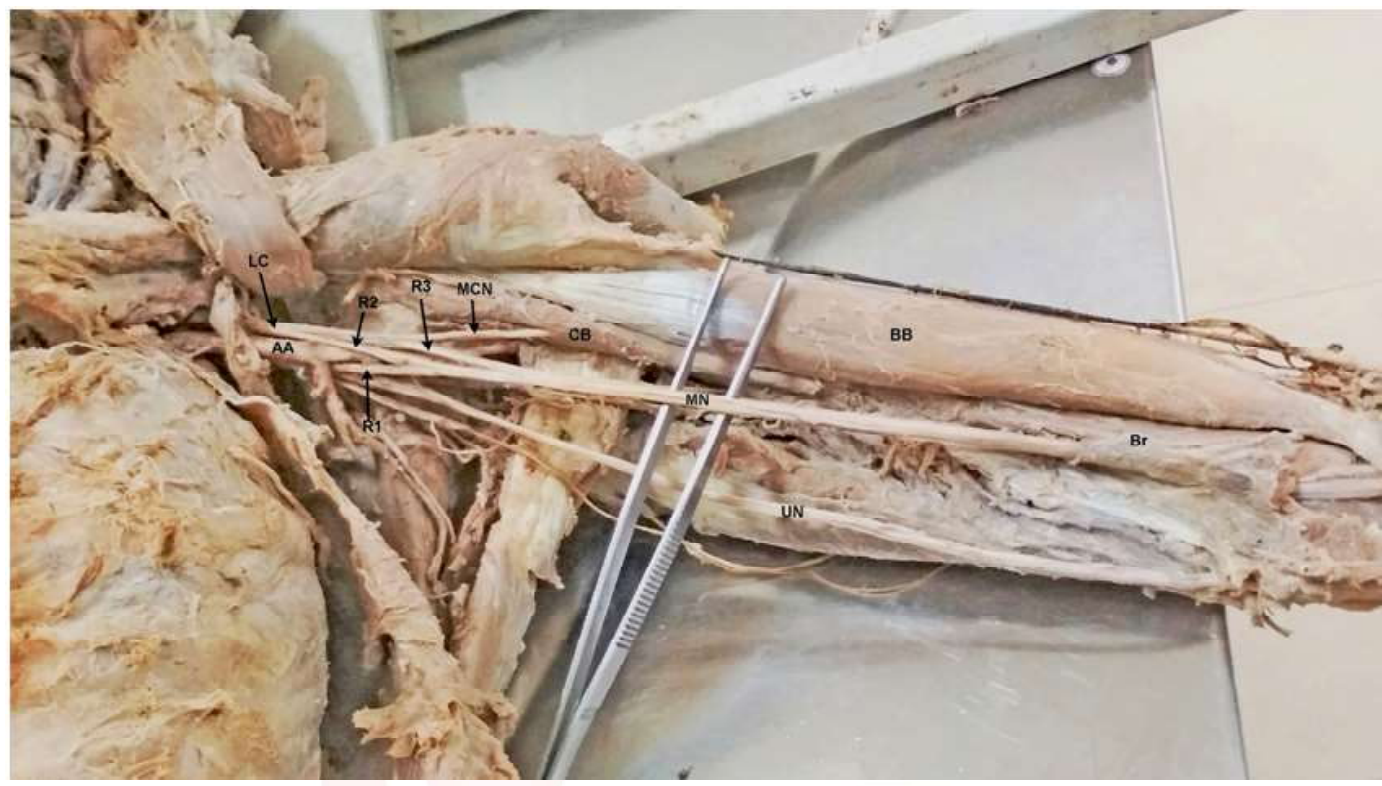

AA: Axillary artery, LC: lateral cord, MCN : Musculocutaneous nerve, MN : Median nerve, R1: Medial root of median nerve, R2: Lateral root of median nerve, R3: Accessory lateral root, UN: Ulnar nerve, CB: Coracobrachialis, BB: Biceps brachii, Br: Brachialis

Fig. 2: Showing accessory lateral root of median nerve arising from lateral cord.

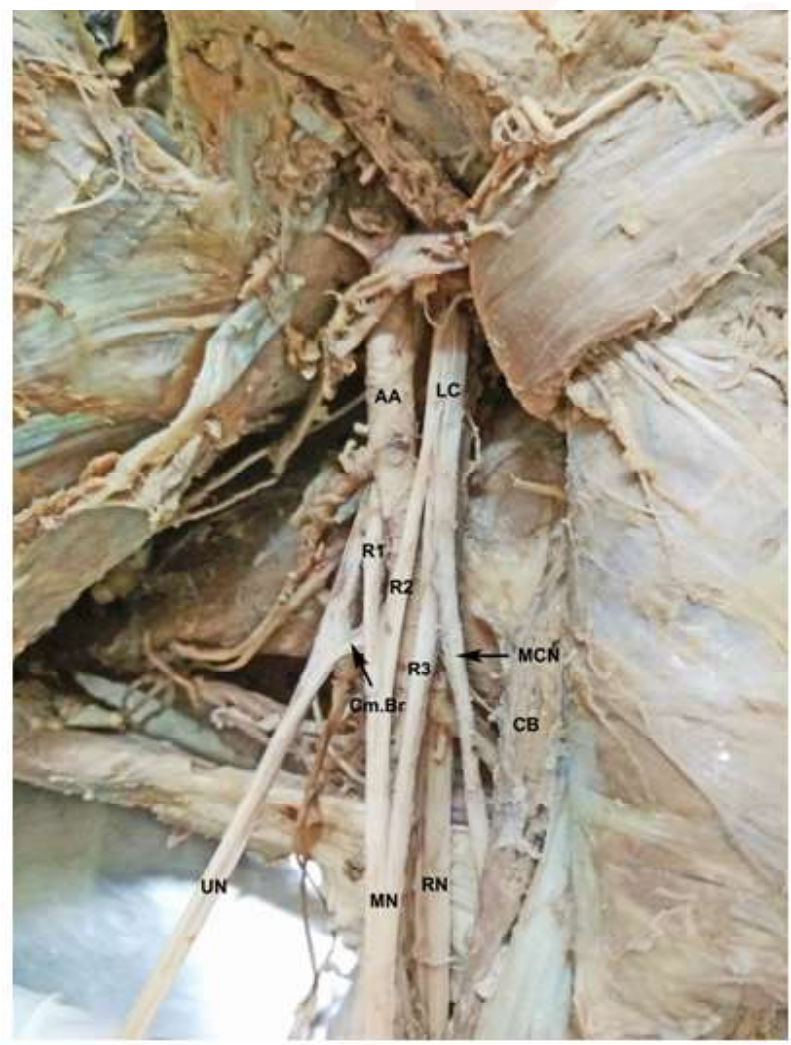

AA : Axillary artery, LC: lateral cord,

MCN : Musculocutaneous nerve, MN : Median nerve, R1: Medial root of median nerve, R2: Lateral root of median nerve, R3: Accessory lateral root, UN: Ulnar nerve, $\mathrm{CB}$ : Coracobrachialis, $\mathrm{Cm}$. $\mathrm{Br}$ :Communicating branch, RN: Radial nerve

descended medially to unite with the medial root (R1) forming the main trunk of the median nerve in front of the axillary artery(AA). The accessory lateral root (R3) was found to arise from the lateral cord in conjunction with the musculocutaneous nerve (MCN), $20 \mathrm{~mm}$ below the coracoid process. The musculocutaneous nerve then pierced coracobrachialis (CB) while the accessory lateral root (R3) descended medially to unite with the main trunk of the median nerve in the upper part of the arm. A communicating branch (Cm.br.)between the medial root(R1) and the ulnar nerve(UN) was also observed. Another interesting finding noted in this case was that the variant left median nerve on entering the anterior compartment of the arm, was found to supply the brachialis muscle ( $\mathrm{Br})$. No other variations were observed in the remaining anatomical course and distribution of the median nerve in the left upper limb. The musculocutaneous nerve showed normal course and distribution and supplied the muscles of anterior compartment of arm namely coracobrachialis(CB), biceps brachii(BB) and brachialis(Br) after which it continued as lateral cutaneous nerve of forearm. The course and distribution of the median nerve on the right side was normal.

\section{DISCUSSION}

Anatomical variations of the brachial plexus and its branches assume considerable clinical importance during various surgical procedures as well as in evaluation and treatment of nerve injuries. The authors observed in the literature 
search that the median nerve may often present variations in its formation, course and distribution. Here we have observed a numerical variation in median nerve formation by two lateral roots arising from lateral cord and one medial root from medial cord of brachial plexus. Similar findings of an additional lateral root from the lateral cord have been described by Emamhadi [2] in 19\%, Budhiraja [3] in 16.1\% and Fazan [4] etal in 52\% cases respectively. Median nerve formation by four $[5,6,7]$ and even five roots by Natsis[8] have been reported in the literature. Samarawickrama [7] classified variations in median nerve root formations into numerical (Type I) and morphological (Type II) groups. Of the type I variations observed by Samarawic krama [7], median nerve was found to have 2 lateral roots in $6.12 \%$ cases and 2 medial roots in $1.02 \%$ cases coming from corresponding cords of brachial plexus. Such accessory roots are more prone to lesions during surgical exploration and can cause unusual sensory loss after surgical intervention in the axilla [8].

The presence of communicating branches between the terminal branches of the brachial plexus is common and maybe of importance in the evaluation of unexplained sensory loss after trauma or surgical intervention in a particular area [4]. The authors in this case observed a communicating branch between the medial root of median nerve and the ulnar nerve. This communication is easily explainable by the fact that both ulnar nerve as well as medial root of median nerve arise as terminal branches of medial cord of brachial plexus. The medial cord of brachial plexus is the continuation of anterior division of lower trunk contributed only by the eighth cervical and first thoracic nerves [9]. In this case, probably some additional fibres of ulnar nerve arising from medial cord would have transiently changed their course to be directed into the medial root of median nerve before joining the ulnar nerve again through the communicating branch.

The Brachialis is mainly innervated by the musculocutaneous nerve (C5 and 6), and a small part by the radial nerve [1]. In this case, we observed that the brachialis muscle was supplied by the median nerve in addition to its main supply by the musculocutaneous nerve.

The median nerve has been often found to supply the flexor muscles of arm in case of deficiency or damage to musculocutaneous nerve $[10,11]$. Sung-Yoon Won [12] observed 4 types of innervation of brachialis muscle in his study ranging from a single, double or triple innervation pattern by musculocutaneous, radial and median nerves. According to Sung-Yoon Won's classification, we observed a Type III innervation pattern in this case with brachialis receiving dual innervation from both musculocutaneous and median nerves. This type of innervation pattern may partially weaken arm flexion causing atypical flexor paresis in case of median nerve injury in the axilla or arm.

The variant formation and distribution of the median nerve observed in this case may be explained embryologically. During the fifth gestational week, the fetus develops forelimb muscles due to regional expression of the homeobox $D$ genes in the mesenchyme of the paraxial mesoderm. The growth cones of the motor axons arrive at the base of the limb bud to form the brachial plexus and continue into the limb bud. The growth cones are guided by many chemoattractants and chemorepulsantssuch as brain-derived nerve growth factor, c-kit ligand, neutrin-1, neutrin-2, slits, semaphorins and ephrins-which work in a highly coordinated manner so that the correct growth cones reach their target before halting and forming synapses. Somatic motor and sensory fibres synapse directly with their target organs [13]. A deflection from this normal embryological growth pattern results in anatomical variations.

Knowledge of median nerve variations is important to anatomists, radiologists, anaesthe siologists and surgeons for help in diagnosis and surgical treatment of shoulder joint, repair operations of axilla and shoulder, radical neck dissections and in management of fracture, dislocations of surgical neck of humerus which can prevent any post-operative complications during surgery [14].

\section{CONCLUSION}

Variant neural formations are usually vulnerable to iatrogenic injury and complications. Knowledge of such variations is academically 
interesting to the anatomist and helpful for the dedicated clinicians. Proper and timely recognition of such variations during anaesthetic blockade and surgical procedures will prove useful to reduce morbidity and improve treatment outcome and recovery.

\section{ABBREVIATIONS}

AA - Axillary artery BB - Biceps brachii

$\mathrm{Br}$ - Brachialis CB - Coracobrachialis

$\mathrm{Cm} . \mathrm{Br}$ - Communicating branchLC - Lateral cord

MCN - Musculocutaneous nerve

MN - Median nerve

R1 - Medial root of median nerve

$\mathbf{R 2}$ - Lateral root of median nerve

R3 - Accessory lateral root of median nerve

RN - Radial nerve UN - Ulnar nerve

\section{Conflicts of Interests: None}

\section{REFERENCES}

[1]. Standring S. The median nerve. Gray's Anatomy. 40th edition. Edinburgh: Churchill Livingstone; 2008:822-828

[2]. Emamhadi M, Chabok SY, Samini F etal. Anatomical Variations of Brachial Plexus in Adult Cadavers; A Descriptive Study. Arch Bone Jt Surg. 2016; 4(3): 253258.

[3]. Budhiraja V, Rastogi R, Asthana AK. Variations in the formation of the median nerve and its clinical correlation. Folia Morphol.2012; 71(1): 28-30.

[4]. Fazan VPS, Amadeu AS, Caleffi AL, Rodrigues Filho OA. Brachial Plexus Variations in its Formation and Main Branches. Acta Cir. Bras. 2003; 18(5): 14-18.

[5]. Uzun A, Seelig LL Jr. A variation in the formation of the median Nerve; communicating branch between the musculocutaneous and median nerves in man. Folia Morphol (warsz). 2001; 60(2):99-101.

[6]. Meshram SW, Khobragade KJ, Pandit SV, Jadhav JS. Four roots of median nerve and its surgical and clinical significance. Int J Anat Var (IJAV). 2012; 5: 110-112.
[7]. Samarawickrama M B.A study of anatomical variations of median nerve formation and its relation to the arteries in the axilla and arm. Int. J. Morphol.2017; 35(2):698-704.

[8]. Natsis K, Paraskevas G, Tzika M. Five roots pattern of median nerve formation. Acta Medica (Hradec Králové) 2016; 59(1):26-28.

[9]. Hollishead WH.Textbook of Anatomy.3rd Edition. Calcutta: Oxford and IBH Publishing Co; 1979: 184190.

[10]. Raza K, Singh S, Rani N, Mishra R, Mehta K, Kaler S. Anomalous Innervation of the Median Nerve in the Arm in the Absence of the Musculocutaneous Nerve. Sultan Qaboos University Med J. 2017; 17(1): e106108.

[11]. Uzel AP, Bulla A, Steinmann G, LaurentJoye M, Caix P. Absence of the musculocutaneous nerve and its distribution from median nerve: About two cases and literature review.Morphologie.2011;95(311):146150.

[12]. Won SY, Cho YH, Choi YJ, Favero V. Intramuscular Innervation Patterns of the Brachialis Muscle. Clinical Anatomy.2015; 28:123-127.

[13]. Schoenwolf GC, Bleyl SB, Brauer PR, Francis-West $\mathrm{PH}$. Larsen's Human Embryology.4th edition. London, UK: Churchill Livingstone; 2008. 311"312.

[14]. Patil ST, Meshram MM, Kasote AP, Kamdi NY. Formation of median nerve from single root on left side and communicating branch from median nerve to musculocutaneous nerve on right side. Morphologie.2012;96: 51-54.
How to cite this article:
Deepa Devadas, Jessie James, Ganesh Nathuramji Trivedi.
VARIANT FORMATION AND DISTRIBUTION OF MEDIAN NERVE.
Int J Anat Res 2018;6(3.2):5554-5557. DOI: $10.16965 /$ ijar.2018.280 